\title{
Medial Meniscus Repair in Major League Soccer Players Results in Decreased Performance Metrics for One Year and Shortened Career Longevity
}

\section{David Heath \\ David Momtaz (D) \\ Abdullah Ghali \\ Luis Salazar \\ Jonathan Bethiel \\ Boris Christopher \\ Caitlyn Mooney \\ Katherine C Bartush}

UT Health San Antonio, Department of Orthopaedics, San Antonio, TX, 78249, USA
Correspondence: Katherine C Bartush UT Health San Antonio, Department of Orthopaedics, 7703 Floyd Curl Dr, MC7774, San Antonio, Tx, 78229-3900, USA Tel + |-574-5|4-2499

Fax +| -2I0-567-5I 25

Email bartush@uthscsa.edu
Background: The rate of medial meniscus tear (MMT) in professional soccer players is high. There are no studies on objective performance metrics following medial meniscus repair in these athletes.

Purpose: Examine the impact of MMT treated with surgical repair on performance metrics and career longevity in Major League Soccer (MLS) players.

Methods: MLS players who sustained an MMT between 1993 and 2019 were identified via publicly available databases. These players were each matched to 2 uninjured controls by debut date, experience, position, race, ethnicity, height, weight, and body mass index (BMI). Demographic data and performance metrics were then collected for both groups. Matches, minutes, goals, assists, shots, shots on target, duels, and duel percentage won are collectively referred to as performance metrics. Statistical analysis compared demographic distributions and performance metrics between the MMT and control groups.

Results: Thirty-three MLS players who had undergone medial meniscus repair were identified and matched to 66 controls. All performance metrics decreased in the MMT group when compared to their controls in the first year after injury. This difference remained significant even when the performance metrics were normalized with respect to time, indicating that the injured players both played less and were not as productive. At 2 years after injury, performance metrics returned to pre-injury levels and were equivalent to those of the healthy controls. Career length was found to be significantly different between the two groups at 8.81 \pm 3.9 years for the MMT group and $12.63 \pm 3.51$ years for the control group $(P<0.001)$.

Conclusion: MLS players undergoing medial meniscus repair had decreased performance metrics in the first year after injury but returned to baseline levels of play at the second year after injury. Their careers were also shorter than those of their uninjured controls.

Keywords: meniscus tear, soccer, return to play, return to sport

\section{Introduction}

Soccer is a worldwide sport that exposes players to a high frequency of lower extremity injuries that primarily impact the knees and ankles. ${ }^{1}$ Meniscal tears account for $8 \%$ of these injuries. ${ }^{2,3}$ In the general population, medial meniscus tear (MMT) is the second most common injury to the knee with an incidence of 61 cases per 100,000 individuals. ${ }^{3}$ In a systematic review by Flanigan et al, meniscus tears were the most prevalent knee injury among the 931 athletes comprised mainly of football and basketball players, occurring in $47 \%$ of all athletes. ${ }^{4}$ Despite the popularity of soccer and the incidence of medial meniscus injuries, there are no studies that report player performance and longevity after medial meniscus repair. 
Nawabi et al investigated return to play (RTP) for professional soccer players after lateral or medial meniscectomy in ninety soccer players operated on by a single surgeon. Their return to play for medial meniscus tears was 5 weeks with the probability of return to play being 5.99 times greater after medial meniscectomy compared to controls $(\mathrm{p}<0.001){ }^{2}$ However, this study does not investigate player performance or longevity after treatment. Additionally, meniscus repair is not considered. In studies that did investigate the effect of meniscal repair on function in professional soccer players, knee questionnaires and subjective measures were used rather than objective performance metrics. ${ }^{5-7}$ Various other studies have focused on medial meniscus magnetic resonance imaging findings in both symptomatic and asymptomatic professional soccer players. In a cross-sectional study, Bezuglov et al examined the magnetic resonance imaging findings of 94 knee joints in 47 professional soccer players. They identified meniscal lesions in $97.8 \%$ of joints and cartilage lesions in both knees in $97.9 \%$ of soccer players. ${ }^{8}$

The purpose of our retrospective review is to investigate the impact of medial meniscus repair on player performances and longevity in Major League Soccer (MLS), the top tier professional soccer league in the United States of America. We hypothesize that players will have reduced performance metrics after medial meniscus repair. We also hypothesize that the injured players will have a shorter career than their uninjured counterparts.

\section{Methods}

A retrospective review of MLS players with medial meniscus injuries from 1993 to 2019 was performed. Players and performance metrics were identified using publicly available resources, such as MLS.com, team websites, news reports, and internet searches. ${ }^{1-4,9-12}$ Medial meniscus injury reports and surgical repair had to be verified by at least two distinct independent resources to meet inclusion criteria. To ensure a player was injured at the time these articles noted, their player profiles were checked to make certain no games were played during their supposed recovery time. Exclusion criteria included concurrent injury, playing in a league other than MLS post-injury, being injured in 2019 (as these players did not have complete data sets), repeat medial meniscus injury, treatment other than a surgical repair including but not limited to meniscectomy, and those who did not RTP. A matched cohort of 2 healthy control players for each injured player was identified. Control players were all determined to have remained without injury 2 years before or after the index year (the year corresponding to the injury year in the MMT cohort).

Variables were collected for each player 2 seasons before and after their injury. Two matched healthy control players were identified for each injured player who matched with age, height $(\mathrm{cm})$, weight $(\mathrm{kg})$, race, ethnicity, years played in the MLS, position, and BMI. The variables collected included date of birth, race, ethnicity, date of injury, date of return, extremity injured, whether surgically or conservatively managed, player position, player dominant leg, height, weight, BMI, debut date, retirement date (if applicable), matches played, minutes played, goals, assists, shots, shots on target (shot OT), number of duels and percentage of duels won (duel $\% \mathrm{~W})$. Experience, career length, and RTP were calculated based on the previously collected variables. Experience is defined as the number of years the athlete played in the MLS prior to injury. Career length is the number of years in which the athlete had actively played professional soccer, whether in MLS or not. RTP is defined as the number of months it took for the athlete to return to playing in the MLS after injury.

Goals are awarded points for any player who scores past a goalkeeper, resulting in one point per shot. A shot is any attempt towards the goal with the intention of scoring. A shot on target is a shot that would have successfully resulted in a score had it not been deflected by the goalkeeper or other defensive player. An assist is tallied for any player that passes the ball to their teammate and that teammate successfully shoots and scores a goal. A duel is an attempt between two players looking to take possession of a ball in the air from the dueling opponent. Duel percentage is the percentage of won possessions over another player for the ball. Minutes played are the total minutes spent by a player on the field in a given season. Matches played is the number of matches played by a player per season. If the minutes played variable was significantly different between cohorts or between pre- and post-index year, normalization of all performance metrics was made with respect to time. The normalization for performance metrics of goals, assists, shots, shots on target, and duels were calculated. The calculation of these performance metrics was achieved by taking the number of minutes played and dividing it by the number of minutes in a standard match, 90 minutes. This new value gave us a quotient that would be used to divide the performance metrics of interest. We then took the performance metrics 
(ie, goals) and divided it by the quotient (ie, goals/quotient), yielding a value that was normalized with respect to time. This normalized value prevented the minutes played variable from skewing the data.

The injured cohort was matched with healthy controls who matched the sample's age, body mass index (BMI), height $(\mathrm{cm})$, weight $(\mathrm{kg})$, race, ethnicity, and experience. Professional debut dates were also kept to within 1 year of the MMT cohort. While age was used to match the MMT cohort to their controls, priority was given to the experience variable since time spent playing a sport was more indicative of performance than athletes age. ${ }^{1-3,10}$ The index year for control players was matched with the injury year for injured players and used to collect preand post-index data for the controls. Demographic and performance metrics were collected for the controls in the same manner as the MMT cohort.

\section{Statistical Analysis}

The sample was then divided into two separate cohorts, those in the MMT cohort and those in the control group. The MMT group underwent a further analysis for their pre-index performance metrics compared to post-index. These divisions were premised on our hypothesis that performance for the MMT cohort would be significantly lower in their post-injury games when compared to their healthy teammates or when compared to their own preinjury performance. We then tabulated and analyzed the collected variables using commercially available software packages. Microsoft Excel was used to sort and organize the data and perform preliminary analysis. International Business Machines (IBM) Statistical Package for the Social Sciences (SPSS) suite was utilized to further analyze the data. Confidence intervals were set at $95 \%$ with a $p$-value of 0.05 being considered statistically significant.

Mean values for age, weight, height, BMI, experience, career length, and RTP were then calculated. Mean values for all performance metrics were also calculated as well as the normalized performance metrics. Pearson's correlations coefficients were obtained for age, BMI, experience, position, height, and weight against RTP. Cross tabulations of categorical variables were analyzed with chi-square and Fisher's exact test where appropriate. A multiple regression model was created and run to assess the relationship between age, BMI, experience, position, race, and ethnicity to RTP.
Categorical data are reported as counts with their respective percentages within the columns. Continuous data are reported as means with their standard deviations. All data was analyzed first to ensure a felicitous statistical test was chosen for its assessment. Comparison of means was performed with independent sample $t$ tests. For independent samples $t$ test analysis, data was shown to meet the assumption of independence and normality as well as homogeneity of variance, alpha was set to 0.05 . when the event data were not normally distributed, the Wilcoxon rank-sum test was performed. Comparison of proportions was made via the Fisher's Exact test for two-by-two assessments, and chi-square cross tabulations for larger tables such as player positions. Correlations were assessed using the Pearson correlation coefficient tests to elucidate connections between our variables of interest and RTP. After ensuring the normal distribution of data, comparison of pre-index to post-index performance metrics was done through a paired samples $t$ test. For non-normally distributed data the Wilcoxon signed-rank tests were used. The multiple linear regression model was analyzed to ensure that all assumptions were met. The data was shown to have a linear relationship between the independent variables and RTP. Residuals were assessed for normal distribution and no multicollinearity was observed. Further, the data showed homoscedasticity. All variables in the multiple linear logistic regression model were first run separately to ensure no artifact $P$ values were present and that all effect sizes were reported honestly. No significant interactions were seen between the independent variables.

\section{Results}

\section{Demographics}

A total of 117 players with MMT were identified between 1993 and 2019. The final sample size for the MMT cohort was 33 players after implementation of exclusion criteria. Sixty-six total uninjured controls were utilized in the study. The subject selection process is outlined in the flow diagram in Figure 1.

For the entire sample of 99 players, the mean age was $26.17 \pm 4.4$ years. The mean BMI in the sample was 23.59 $\pm 1.52 \mathrm{~kg} / \mathrm{m}^{2}$. Average experience was $4.89 \pm 1.94$ years. $72.70 \%$ of the sample were white, with the remaining players being Black. $33.33 \%$ of the players were Hispanic. $33.33 \%$ of the players were left leg dominant. Of the injured players, $54.60 \%$ injured their left legs. The 


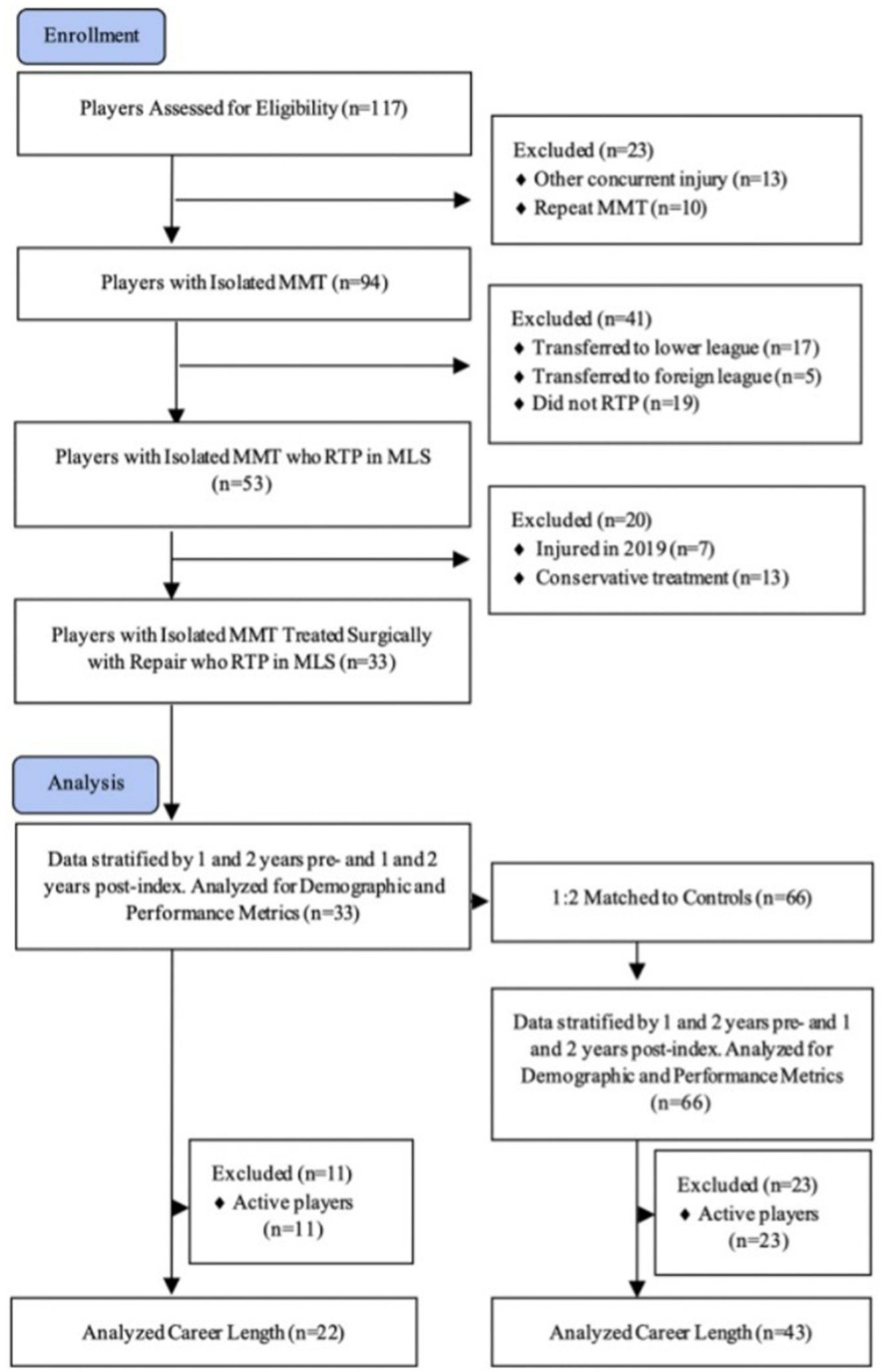

Figure I Subject selection process flow diagram.

MMT cohort had equal numbers of defenders, forwards, and midfielders $(11,11,11)$, resulting in the same distribution of players within the control group $(22,22,22)$. When analyzed for proportional significance, player position, race, ethnicity, and leg dominance showed no statistical difference between the MMT and control groups. Further, 
statistical analysis of age, weight, height, BMI, and experience showed no significant difference between the MMT group and the controls. However, when the career length of the retired MMT players was compared to that of the retired control players, $8.81 \pm 3.90$ years and $12.63 \pm 3.51$ years, respectively, a significant difference was observed $(P<0.001)$. Demographic characteristics are outlined in Tables 1 and 2.

\section{Return to Sport and Career Length}

A total of 117 MLS players with a history of MMT were identified between 1993 and 2019. Of these players, injury forced retirement in 19, yielding an RTP rate of $83.77 \%$. For players who did RTP, the mean RTP time was 5.53 months. The mean RTP for the MMT cohort was 5.31 months with no statistically significant difference to the overall sample's RTP $(P=0.125)$. At the time of analysis, 22 players in the MMT cohort and 43 in the control group had retired. While the proportion of retirement was not significantly different between groups $(P=0.239)$, the respective career lengths differed. Injured players demonstrated a shorter career length, averaging $8.81 \pm 3.90$ years, while the control group had an average of $12.63 \pm 3.51$ years $(P<0.001)$. However, RTP itself was not correlated with career length $(P=0.183)$. Correlation analysis of age, BMI, position, height, and weight found no correlation with RTP. However, players with more seasons played prior to their injury had an increased time to RTP ( $\mathrm{r}=$ $0.265, P=0.045$ ). Multiple linear regression analysis demonstrated that as experience increased by 1 year,

Table I Population Demographics

\begin{tabular}{|l|l|c|c|c|}
\hline \multicolumn{2}{|l|}{} & $\begin{array}{c}\text { MMT } \\
\text { (N = 33) }\end{array}$ & $\begin{array}{c}\text { Controls } \\
(\mathbf{N}=66)\end{array}$ & P value \\
\hline Position & Defender & II (33) & $22(33)$ & 1.00 \\
& Forward & II(33) & $22(33)$ & \\
& Midfielder & II (33) & $22(33)$ & \\
\hline Race & White & $24(73)$ & $48(73)$ & 1.00 \\
& Black & $9(27)$ & $18(27)$ & \\
\hline Ethnicity & Non-Hispanic & $22(66)$ & $45(68)$ & 0.880 \\
& Hispanic & II (33) & $21(32)$ & \\
\hline Leg & Left & $11(33)$ & $22(33)$ & 0.584 \\
Dominance & Right & $22(66)$ & $44(66)$ & \\
\hline Leg Injured & Left & $18(55)$ & & \\
& Right & $15(45)$ & & \\
\hline
\end{tabular}

Notes: Demographic characteristics of the MMT and control groups with respect to position, race, ethnicity, leg dominance, and leg injured. Values are given as $n$ (\%).
Table 2 Population Demographics at Time of Injury

\begin{tabular}{|c|c|c|c|}
\hline & $\begin{array}{l}\text { MMT } \\
(\mathbf{N}=33)\end{array}$ & $\begin{array}{l}\text { Controls } \\
(N=66)\end{array}$ & \\
\hline & Mean (SD) & Mean (SD) & $P$ value \\
\hline Age (years) & $26.33(4.35)$ & $26.00(4.60)$ & 0.725 \\
\hline Weight (kg) & 76.74 (2.09) & $76.11(1.82)$ & 0.145 \\
\hline Height (cm) & I80.95 (5.5I) & $179.54(5.95)$ & 0.245 \\
\hline BMI $\left(\mathrm{kg} / \mathrm{m}^{2}\right)$ & $23.49(1.47)$ & $23.69(1.68)$ & 0.559 \\
\hline Experience (y) & $4.94(1.97)$ & $4.85(1.99)$ & 0.836 \\
\hline \multirow[t]{2}{*}{ RTP (m) } & 5.31 (2.73) & & \\
\hline & $\begin{array}{l}\text { Retired } \\
(\mathbf{N}=22)\end{array}$ & $\begin{array}{l}\text { Retired } \\
(\mathbf{N}=43)\end{array}$ & \\
\hline Career Length (y) & $8.81(3.90)$ & I $2.63(3.5 I)$ & $<0.001$ \\
\hline
\end{tabular}

Notes: Demographic characteristics of the MMT and control groups with respect age, weight, height, BMI, experience, and RTP. Experience and age are given in years, RTP is given in months. Values are given as mean (SD [Standard Deviation]). Bolded values indicate significance $(P<0.05)$.

RTP increased by 3.48 months even when age, player position, BMI, and leg dominance were controlled for within the MMT cohort $(P<0.038)$. These results are shown in Table 3.

\section{Performance Metrics}

Matches played, minutes played, goals, assists, shots, shots on target, duels, and duel \% won comprise the performance metrics analyzed in this study. Time-normalized (TN) goals, assists, shots, shots on target, and duels were also analyzed when minutes played per season was significantly different between the two comparison groups. Time-normalized variables will have $\mathrm{TN}$ written before their name. No performance metric was found to be statistically significant between the MMT and controls at 1 or 2 years pre-index. These results can be seen in Table 4 .

When performance metrics were analyzed at 1-year post-index, we found that all metrics were significantly different between the MMT and the control group. All non-normalized performance metrics were seen to decrease significantly between the two groups. To ensure that this decrease was not solely due to the decreased minutes played, the normalized data was also compared between the two groups and was found to be significantly reduced for the MMT group when compared to the controls. In other words, the injured players played fewer minutes when compared to their controls, and those minutes were less productive. When data were analyzed for 2 years post-index, nearly all performance metrics were comparable between the two groups except for the number 
Table 3 Correlations of Demographic Characteristics with RTP

\begin{tabular}{|l|c|c|}
\hline & $\mathbf{r}$ & $\boldsymbol{P}$ value \\
\hline Age & 0.063 & 0.368 \\
BMI & 0.154 & 0.205 \\
Experience & $\mathbf{0 . 2 6 5}$ & $\mathbf{0 . 0 4 5}$ \\
Position & -0.045 & 0.809 \\
Height & -0.103 & 0.291 \\
Weight & 0.189 & 0.154 \\
\hline
\end{tabular}

Notes: Pearson correlation coefficients and $P$ values for age, BMI, experience, position, height, and weight. Bolded values indicate significance $(P<0.05)$.

of duels, which averaged 128.48 for the MMT group and 170.93 for the control group $(P=0.033)$. These results are outlined in detail in Table 5.

Performance metrics were then compared between the pre- and post-index years for the MMT and control players. It was found that nearly all performance metrics were significantly lower from pre- to post-index except for the number of duels, which averaged 134.20 and 109.90 for pre- and post-index, respectively $(P=0.153)$. These differences held true even when the normalized values were compared, demonstrating that the reduced performance was independent of the reduced time played. In other words, the injured players played fewer minutes and those minutes were less productive. These findings are further outlined in Table 6 .
Next, we combined the performance metrics for year 1 and 2 pre-index and compared the means to the combined years 1 and 2 post-index, allowing us to observe longer term trends. Fewer performance metrics showed a statistical difference in the MMT cohort when compared to a comparison of only the year before and after the index year. Matches, goals, assists, shots OT, and duel\% $\mathrm{w}$ were lower in the combined years 1 and 2 post-index. However, when the time-normalized variables were analyzed, it was found that no statistically significant differences existed between the combined data. These results are displayed in Table 7.

We then compared 1 year pre-index to 2 years postindex and analyzed all the performance metrics once again. No differences existed between 1 year pre-index to 2 years post-index for the MMT cohort, indicating the players had returned to their baseline level of play. These results are outlined in Table 8 .

\section{Discussion}

The findings of this study show that medial meniscus repair can provide athletes with the same level of play as pre-injury at 2 years following their meniscal repair, but they may be subject to a shortened overall career. It is estimated that every elite male soccer player will sustain about one performance-limiting injury every year. $^{9-11}$

Table 4 Performance Metrics at 2 and I Year Preindex, MMT vs Controls

\begin{tabular}{|c|c|c|c|}
\hline & MMT $(\mathbf{N}=33)$ & Controls $(N=66)$ & \\
\hline & Mean (SD) & Mean (SD) & $P$ value \\
\hline Matches 2 y Pre & $23.00(6.54)$ & $24.69(6.26)$ & 0.26 \\
\hline Minutes 2 y Pre & I558.74 (78I.3I) & $2317.65(429.31)$ & 0.26 \\
\hline Goals 2 y Pre & $5.00(3.52)$ & $5.33(4.44)$ & 0.769 \\
\hline Assists 2 y Pre & $4.09(2.89)$ & $3.88(3.06)$ & 0.777 \\
\hline Shots 2 y Pre & $29.67(17.64)$ & $33.67(16.52)$ & 0.536 \\
\hline Shots OT 2 y Pre & $17.43(12.76)$ & $15.07(12.53)$ & 0.462 \\
\hline Duels 2 y Pre & $130.50(66.97)$ & $197.54(100.33)$ & 0.222 \\
\hline Duel\%W 2 y Pre & $51.386(12.48)$ & $49.89(10.32)$ & 0.68 \\
\hline Matches I y Pre & $21.00(7.42)$ & $24.71(6.32)$ & 0.213 \\
\hline Minutes I y Pre & | $495.83(706.86)$ & I867.56 (7|3.44) & 0.221 \\
\hline Goals I y Pre & $5.84(3.67)$ & $4.85(4.36)$ & 0.379 \\
\hline Assists I y Pre & $5.67(4.97)$ & $4.02(3.07)$ & 0.084 \\
\hline Shots I y Pre & $25.44(20.26)$ & $32.6(27.66)$ & 0.242 \\
\hline Shots OT I y Pre & $12.57(8.92)$ & I4.23 (9.84) & 0.591 \\
\hline Duels I y Pre & I34.20 (7I.84) & $209.5 \mathrm{I}(106.58)$ & 0.207 \\
\hline Duel\%W I y Pre & $52.64(16.15)$ & $50.078(12.11)$ & 0.507 \\
\hline
\end{tabular}

Notes: Variables are given as mean (SD) for performance metrics between the MMT and control cohorts, respective $P$ values are given.

Abbreviations: Y, year; TN, time-normalized; pre, preindex; post, postindex; shots OT, shots on target; duel\%W, duel percentage won; matches, matches played; minutes, minutes played. 
Table 5 Performance Metrics at I and 2 Year Postindex, MMT Vs Controls

\begin{tabular}{|c|c|c|c|}
\hline & MMT (N = 33) & Controls $(N=66)$ & \\
\hline & Mean (SD) & Mean (SD) & $P$ value \\
\hline Matches I y Post & $12.00(9.223)$ & $24.03(6.64)$ & $<0.001$ \\
\hline Minutes ly Post & $1002.03(482.15)$ & I808.42 (672.43) & $<0.001$ \\
\hline Goals I y Post & $2.63(1.49)$ & $8.06(3.39)$ & $<0.001$ \\
\hline Assists I y Post & $1.9(0.84)$ & $3.55(1.05)$ & 0.016 \\
\hline Shots I y Post & I6.4| (7.54) & 30.71 (12.89) & 0.002 \\
\hline Shots OT I y Post & 7.5 (3.89) & | 4.37 (5.26) & 0.006 \\
\hline Duels I y Post & $109.9(24.31)$ & $203.5(24.76)$ & $<0.001$ \\
\hline Duel\%W I y Post & $26.83(6.03)$ & 61.6 (18.39) & 0.02 \\
\hline TN Goals & $0.14(0.25)$ & $0.52(1.05)$ & 0.003 \\
\hline TN Assists & $0.10(0.12)$ & $0.14(0.12)$ & 0.002 \\
\hline TN Shots & $0.88(0.97)$ & $1.64(1.08)$ & $<0.001$ \\
\hline TN Shots OT & $0.33(0.39)$ & $0.74(0.69)$ & 0.034 \\
\hline TN Duels & $5.59(6.44)$ & $7.14(7.62)$ & 0.043 \\
\hline Matches 2 y Post & $19.67(10.95)$ & $22.83(7.44)$ & 0.123 \\
\hline Minutes 2 y Post & $13 \mid 4.52(5 \mid 6.32)$ & $|67| .5 \mid$ (68I.67) & 0.086 \\
\hline Goals 2 y Post & $3.89(1.79)$ & $5.53(2.01)$ & 0.183 \\
\hline Assists 2 y Post & $3.82(2.23)$ & $3.59(1.40)$ & 0.75 \\
\hline Shots 2 y Post & $28.21(6.80)$ & $30.63(6.93)$ & 0.736 \\
\hline Shots OT 2 y Post & $7.43(3.44)$ & $10.53(5.84)$ & 0.196 \\
\hline Duels 2 y Post & | 28.48 (67.88) & I 70.93 (75.97) & 0.033 \\
\hline Duel\%W 2 y Post & $47.07(12)$ & $59.42(15.10)$ & 0.449 \\
\hline
\end{tabular}

Notes: Variables are given as mean (SD) for performance metrics between the MMT and control cohorts, respective $P$ values are given. Time-normalized variables are also provided for I-year postindex. Bolded values indicate significance $(P<0.05)$.

Abbreviations: Y, year; pre, preindex; post, postindex; shots OT, shots on target; duel\%W, duel percentage won; matches, matches played; minutes, minutes played.

Meniscal tears account for $8 \%$ of injuries in professional soccer players. ${ }^{2,3}$ Meniscal tears requiring surgery range from 60 to 70 per 100,000 person-years. ${ }^{6,13}$ These cartilaginous injuries have the potential to affect professional athletes significantly, as soccer already predisposes players to early-onset knee osteoarthritis. ${ }^{14,15}$ Such injuries may have financial repercussions as well given the uncertain impact meniscal tears can have on performance postinjury. However, published literature on meniscal repair outcomes in elite athletes remains sparse. Little is written on the effects of these injuries specific to professional soccer players in the literature. Outcomes following meniscal tears in athletes have mainly focused on their effect on RTP following repair, but specific data evaluating performance upon RTP are scarce. This study expands on prior research by objectively defining the parameters by which meniscal tears, which have undergone repair affect player performance and longevity. The principal finding in the present study was that injured professional soccer players in the MLS returned to pre-injury performance levels two years following their injury. Furthermore, player experience was the only factor significantly associated with increased time to RTP. It was found that for each year increase in experience, RTP increased by 3.48 months even when player position, age, weight, height, BMI, and leg dominance were controlled for $(P<$ 0.038).

Prior reports on meniscal repairs in elite athletes have focused on using functional outcome scores, RTP, and subjective assessments of returning to pre-injury level of competitive play. Rates of return to play are promising, ranging from $80 \%$ to $95 \%$ at an average of around 4 to 6 months following meniscal repair. ${ }^{6}$ Logan et al examined 42 elite athletes following meniscal repair and reported that $81 \%$ of patients returned to a similar pre-injury level of play at an average time of 10.4 months. ${ }^{5}$ However, only $4(8.9 \%)$ of their patients were elite soccer players, and they did not quantify the level of play pre- and post-injury. Tucciarone et al's study on 20 professional soccer players with a meniscal repair demonstrated a $90 \%$ return to play at 2-years follow-up. ${ }^{6}$ These results were measured based on questionnaires sent to patients that similarly cannot objectively demonstrate quantitative effects of meniscal repair on performance metrics. In another study, Alvarez- 
Table 6 Performance Metrics at I Year Pre vs Postindex in MMT and Controls

\begin{tabular}{|c|c|c|c|c|c|}
\hline & & \multicolumn{2}{|l|}{ MMT (N = 33) } & \multicolumn{2}{|l|}{ Controls $(N=66)$} \\
\hline & & Mean (SD) & $P$ & Mean (SD) & $P$ \\
\hline Matches & $\begin{array}{l}\text { I y Pre } \\
\text { I y Post }\end{array}$ & $\begin{array}{l}21.00(7.42) \\
12.00(9.22)\end{array}$ & $<0.001$ & $\begin{array}{l}24.71(6.32) \\
24.03(6.64)\end{array}$ & 0.221 \\
\hline Minutes & $\begin{array}{l}\text { I y Pre } \\
\text { I y Post }\end{array}$ & $\begin{array}{l}\text { I } 495.83(706.86) \\
\text { I } 002.03(482.15)\end{array}$ & 0.039 & $\begin{array}{l}\mid 867.56(7 \mid 3.44) \\
\mid 808.42(672.426)\end{array}$ & 0.246 \\
\hline Goals & $\begin{array}{l}\text { I y Pre } \\
\text { I y Post }\end{array}$ & $\begin{array}{l}5.84(3.67) \\
2.63(1.49)\end{array}$ & 0.014 & $\begin{array}{l}4.85(4.36) \\
8.06(3.39)\end{array}$ & 0.007 \\
\hline Assists & $\begin{array}{l}\text { I y Pre } \\
\text { I y Post }\end{array}$ & $\begin{array}{l}5.67(4.97) \\
1.9(0.84)\end{array}$ & 0.002 & $\begin{array}{l}4.02(3.07) \\
3.55(1.05)\end{array}$ & 0.170 \\
\hline Shots & $\begin{array}{l}\text { I y Pre } \\
\text { I y Post }\end{array}$ & $\begin{array}{l}25.79(20.62) \\
16.41(7.54)\end{array}$ & 0.022 & $\begin{array}{l}32.6(27.66) \\
30.71(12.89)\end{array}$ & 0.275 \\
\hline Shots OT & $\begin{array}{l}\text { I y Pre } \\
\text { I y Post }\end{array}$ & $\begin{array}{l}\text { I } 2.57(8.92) \\
7.50(3.89)\end{array}$ & 0.028 & $\begin{array}{l}\text { I } 4.23(9.84) \\
\text { I } 4.37(5.26)\end{array}$ & 0.475 \\
\hline Duels & $\begin{array}{l}\text { I y Pre } \\
\text { I y Post }\end{array}$ & $\begin{array}{l}\text { I } 34.20(7 \mid .84) \\
\text { I09.9 (24.3I) }\end{array}$ & 0.153 & $\begin{array}{l}209.51(106.58) \\
203.5(24.76)\end{array}$ & 0.428 \\
\hline Duel\%W & $\begin{array}{l}\text { I y Pre } \\
\text { I y Post }\end{array}$ & $\begin{array}{l}52.64(16.15) \\
26.83(6.03)\end{array}$ & 0.003 & $\begin{array}{l}50.07(12.11) \\
61.6(18.39)\end{array}$ & 0.169 \\
\hline TN Goals & $\begin{array}{l}\text { I y Pre } \\
\text { I y Post }\end{array}$ & $\begin{array}{l}0.29(0.26) \\
0.14(0.25)\end{array}$ & 0.016 & $\begin{array}{l}0.18(0.17) \\
0.52(1.05)\end{array}$ & 0.010 \\
\hline TN Assists & $\begin{array}{l}\text { I y Pre } \\
\text { I y Post }\end{array}$ & $\begin{array}{l}0.27(0.34) \\
0.10(0.12)\end{array}$ & 0.022 & $\begin{array}{l}0.16(0.13) \\
0.14(0.12)\end{array}$ & 0.186 \\
\hline TN Shots & $\begin{array}{l}\text { I y Pre } \\
\text { I y Post }\end{array}$ & $\begin{array}{l}1.55(1.31) \\
0.88(0.97)\end{array}$ & 0.007 & $\begin{array}{l}1.58(1.09) \\
1.64(1.08)\end{array}$ & 0.299 \\
\hline TN Shots OT & $\begin{array}{l}\text { I y Pre } \\
\text { I y Post }\end{array}$ & $\begin{array}{l}0.66(0.63) \\
0.33(0.39)\end{array}$ & 0.014 & $\begin{array}{l}0.67(0.73) \\
0.74(0.69)\end{array}$ & 0.293 \\
\hline TN Duels & $\begin{array}{l}\text { I y Pre } \\
\text { I y Post }\end{array}$ & $\begin{array}{l}7.25(4.53) \\
5.59(6.44)\end{array}$ & 0.153 & $\begin{array}{l}18.27(10.53) \\
7.14(7.62)\end{array}$ & 0.198 \\
\hline
\end{tabular}

Notes: Variables are given as mean (SD) for performance metrics between pre and postindex years in the MMT and control cohorts on the left and right, respectively. Respective $P$ values are also provided. Bolded values indicate significance $(P<0.05)$.

Abbreviations: Y, year; TN, time-normalized; pre, preindex; post, postindex; shots OT, shots on target; duel\%W, duel percentage won; matches, matches played; minutes, minutes played.

Diaz et al evaluated 29 elite soccer players following meniscal repair with more than five years of follow-up. ${ }^{1}$ They reported that $89.6 \%$ returned to pre-injury level of sport at a mean of 4.3 months in those who underwent meniscal repair alone. Their activity levels pre- and postinjury were assessed using the Tegner activity scale, a standardized, numerical method for evaluating activity levels with good reliability and validity. ${ }^{16-19}$ Yet, this scale stratifies levels of activity into categories subject to variable interpretation by patients. In other words, their general activity level may be adequately assessed without providing objective data, the way our study does, on how their meniscal repair has affected their performance. Several studies have replicated improvements in Tegner, Lysholm and International Knee Documentation Committee (IKDC) scores following meniscal repair. ${ }^{15,20-23}$ However, these studies similarly lack the objective performance metrics pre- and post-injury.

The main strength of our study is the objective evaluation of performance pre- and post-injury. This study is the first to use these metrics to analyze professional soccer player performance following medial meniscal repair. As professional soccer players depend on their performance for their livelihood and their absence may affect team 
Table 7 Performance Metrics Combined I and 2 Years Pre vs I and 2 Years Postindex in MMT and Controls

\begin{tabular}{|c|c|c|c|c|c|}
\hline & & \multicolumn{2}{|l|}{ MMT (N = 33) } & \multicolumn{2}{|l|}{ Controls $(N=66)$} \\
\hline & & Mean (SD) & $P$ & Mean (SD) & $P$ \\
\hline Matches & $\begin{array}{l}\text { y } I \text { and } 2 \text { Pre } \\
\text { y } I \text { and } 2 \text { Post }\end{array}$ & $\begin{array}{l}21.98(6.84) \\
15.84(10.26)\end{array}$ & $<0.001$ & $\begin{array}{l}24.63(6.24) \\
23.43(7.05)\end{array}$ & 0.047 \\
\hline Minutes & $\begin{array}{l}\text { y } I \text { and } 2 \text { Pre } \\
\text { y } I \text { and } 2 \text { Post }\end{array}$ & $\begin{array}{l}\text { I } 527.29(7 \mid 6.88) \\
\text { I I } 58.28(936.57)\end{array}$ & 0.042 & $\begin{array}{l}2092.67(2477.36) \\
1739.25(726.48)\end{array}$ & 0.058 \\
\hline Goals & $\begin{array}{l}\text { y } I \text { and } 2 \text { Pre } \\
\text { y } I \text { and } 2 \text { Post }\end{array}$ & $\begin{array}{l}5.42(3.85) \\
3.26(3.37)\end{array}$ & 0.023 & $\begin{array}{l}5.07(4.41) \\
6.79(5.25)\end{array}$ & 0.014 \\
\hline Assists & $\begin{array}{l}\text { y } I \text { and } 2 \text { Pre } \\
\text { y } I \text { and } 2 \text { Post }\end{array}$ & $\begin{array}{l}4.89(4.43) \\
2.86(2.27)\end{array}$ & 0.002 & $\begin{array}{l}3.95(3.09) \\
3.57(2.78)\end{array}$ & 0.180 \\
\hline Shots & $\begin{array}{l}\text { y } I \text { and } 2 \text { Pre } \\
y I \text { and } 2 \text { Post }\end{array}$ & $\begin{array}{l}27.55(23.73) \\
22.31(30.10)\end{array}$ & 0.214 & $\begin{array}{l}33.14(26.24) \\
30.67(24.87)\end{array}$ & 0.234 \\
\hline Shots ON & $\begin{array}{l}\text { y } I \text { and } 2 \text { Pre } \\
\text { y } I \text { and } 2 \text { Post }\end{array}$ & $\begin{array}{l}15.03(13.20) \\
7.47(7.70)\end{array}$ & $<0.001$ & $\begin{array}{l}14.65(12.44) \\
12.46(11.85)\end{array}$ & 0.056 \\
\hline Duels & $\begin{array}{l}\text { y } I \text { and } 2 \text { Pre } \\
\text { y } I \text { and } 2 \text { Post }\end{array}$ & $\begin{array}{l}\text { I32.36 (68.87) } \\
\text { II9.19 (100.25) }\end{array}$ & 0.120 & $\begin{array}{l}203.53(102.02) \\
I 87.22(84.29)\end{array}$ & 0.086 \\
\hline Duel\%W & $\begin{array}{l}\text { y } I \text { and } 2 \text { Pre } \\
\text { y } I \text { and } 2 \text { Post }\end{array}$ & $\begin{array}{l}51.98(15.02) \\
36.95(24.74)\end{array}$ & 0.006 & $\begin{array}{l}49.98 \text { (II.48) } \\
60.51(67.40)\end{array}$ & 0.189 \\
\hline TN Goals & $\begin{array}{l}\text { y } I \text { and } 2 \text { Pre } \\
\text { y } I \text { and } 2 \text { Post }\end{array}$ & $\begin{array}{l}0.23(0.24) \\
0.23(0.38)\end{array}$ & 0.493 & $\begin{array}{l}0.20(0.25) \\
0.39(0.84)\end{array}$ & 0.007 \\
\hline TN Assists & $\begin{array}{l}\text { y } I \text { and } 2 \text { Pre } \\
\text { y } I \text { and } 2 \text { Post }\end{array}$ & $\begin{array}{l}0.21(0.27) \\
0.13(0.21)\end{array}$ & 0.069 & $\begin{array}{l}0.15(0.12) \\
0.15(0.14)\end{array}$ & 0.407 \\
\hline TN Shots & $\begin{array}{l}\text { y } I \text { and } 2 \text { Pre } \\
\text { y } I \text { and } 2 \text { Post }\end{array}$ & $\begin{array}{l}1.38(1.36) \\
1.70(3.03)\end{array}$ & 0.199 & $\begin{array}{l}1.56(1.10) \\
1.74(1.98)\end{array}$ & 0.125 \\
\hline TN Shots OT & $\begin{array}{l}\text { y } I \text { and } 2 \text { Pre } \\
\text { y } I \text { and } 2 \text { Post }\end{array}$ & $\begin{array}{l}0.63(0.62) \\
0.61(1.00)\end{array}$ & 0.454 & $\begin{array}{l}0.67(0.64) \\
0.61(0.60)\end{array}$ & 0.198 \\
\hline TN Duels & $\begin{array}{l}\text { y } I \text { and } 2 \text { Pre } \\
\text { y } I \text { and } 2 \text { Post }\end{array}$ & $\begin{array}{l}5.99(5.22) \\
9.49(18.12)\end{array}$ & 0.074 & $\begin{array}{l}11.19(6.09) \\
7.50(10.60)\end{array}$ & 0.288 \\
\hline
\end{tabular}

Notes: Variables are given as mean (SD) for performance metrics between I and 2 years combined pre and I and 2 years combined postindex years in the MMT and control cohorts on the left and right, respectively. Respective $P$ values are also provided. Bolded values indicate significance $(P<0.05)$.

Abbreviations: Y, year; TN, time-normalized; pre, preindex; post, postindex; shots OT, shots on target; duel\%W, duel percentage won; matches, matches played; minutes, minutes played.

performance, these findings provide objective evidence with which physicians may counsel patients.

This study is not without limitations. Retrospective studies like ours have biases inherent to the data retrieval, selection bias and interpretation processes. Additionally, our study did not record the type of medial meniscal repair (inside-out, all-inside, or open repair) that each patient underwent, potentially biasing our results as these techniques may lead to different outcomes. Furthermore, goalkeepers were excluded from the analysis due to their incompatible performance metrics. Our study also excluded those who received conservative treatment. We recommend future studies examining the performance and longevity of goalkeepers. Additionally, the external validity of our study is limited. This study focuses on elite athletes with a high physiologic reserve, a high level of motivation to RTP, and access to world-class rehabilitation, which may not be available to most patients. Future studies on lower levels of competitive athletes and the general population are recommended to provide more generalizable results. Lastly, since our goal was to examine the effects of players who underwent medial meniscus repair compared to matched healthy controls, there was no treatment arm for patients with an MMT who 
Table 8 Performance Metrics at I Year Preindex vs 2 Years Postindex in MMT and Controls

\begin{tabular}{|c|c|c|c|c|c|}
\hline & & \multicolumn{2}{|l|}{ MMT (N = 33) } & \multicolumn{2}{|c|}{ Controls $(\mathrm{N}=66)$} \\
\hline & & Mean (SD) & $P$ & Mean (SD) & $P$ \\
\hline Matches & $\begin{array}{l}\text { I y Pre } \\
2 \text { y Post }\end{array}$ & $\begin{array}{l}21.01(7.42) \\
19.67(10.95)\end{array}$ & 0.401 & $\begin{array}{l}24.71(6.32) \\
22.83(7.44)\end{array}$ & 0.114 \\
\hline Minutes & $\begin{array}{l}\text { I y Pre } \\
2 \text { y Post }\end{array}$ & $\begin{array}{l}\text { I495.83 (706.86) } \\
\text { I3I4.52 (516.32) }\end{array}$ & 0.398 & $\begin{array}{l}1867.56(713.44) \\
1671.51 \text { (78I.67) }\end{array}$ & 0.185 \\
\hline Goals & $\begin{array}{l}\text { I y Pre } \\
2 \text { y Post }\end{array}$ & $\begin{array}{l}5.84(3.67) \\
3.89(1.79)\end{array}$ & 0.545 & $\begin{array}{l}4.85(4.36) \\
5.53(2.01)\end{array}$ & 0.641 \\
\hline Assists & $\begin{array}{l}\text { I y Pre } \\
2 \text { y Post }\end{array}$ & $\begin{array}{l}5.67(4.97) \\
3.82(2.23)\end{array}$ & 0.203 & $\begin{array}{l}4.02(3.07) \\
3.59(1.40)\end{array}$ & 0.352 \\
\hline Shots & $\begin{array}{l}\text { I y Pre } \\
2 \text { y Post }\end{array}$ & $\begin{array}{l}25.79(20.62) \\
28.21(6.80)\end{array}$ & 0.712 & $\begin{array}{l}32.6(27.66) \\
30.63(6.93)\end{array}$ & 0.724 \\
\hline Shots OT & $\begin{array}{l}\text { I y Pre } \\
2 \text { y Post }\end{array}$ & $\begin{array}{l}12.57(8.92) \\
7.43(3.44)\end{array}$ & 0.168 & $\begin{array}{l}14.23(9.84) \\
10.53(5.84)\end{array}$ & 0.126 \\
\hline Duels & $\begin{array}{l}\text { I y Pre } \\
2 \text { y Post }\end{array}$ & $\begin{array}{l}\text { I34.20 (7I.84) } \\
\text { I } 28.48(67.88)\end{array}$ & 0.955 & $\begin{array}{l}209.51 \text { ( } 106.58) \\
170.93(75.97)\end{array}$ & 0.025 \\
\hline Duel\%W & $\begin{array}{l}\text { I y Pre } \\
2 \text { y Post }\end{array}$ & $\begin{array}{l}52.64(16.15) \\
47.07(12)\end{array}$ & 0.375 & $\begin{array}{l}50.07(12.11) \\
59.42(15.10)\end{array}$ & 0.361 \\
\hline
\end{tabular}

Notes: Variables are given as mean (SD) for performance metrics between I year pre and 2 years postindex in the MMT and control cohorts on the left and right, respectively. Respective $P$ values are also provided. Bolded values indicate significance $(P<0.05)$.

Abbreviations: Y, year; TN, time-normalized; pre, preindex; post, postindex; shots OT, shots on target; duel\%W, duel percentage won; matches, matches played; minutes, minutes played.

underwent conservative treatment or who underwent meniscectomy. Future studies should be initiated to compare outcomes in these groups compared to those who underwent medial meniscus repair.

\section{Conclusion}

In conclusion, medial meniscus repair can provide great results for professional athletes aspiring to continue competing at similar pre-injury levels. The present study shows that professional soccer players may expect to return to the same level of play as pre-injury at 2 years following their meniscal repair, but they may be subject to a shortened overall career.

\section{Abbreviations}

BMI, body mass index; Duel\%W, duel percentage won; IBM, International Business Machines; IKDC, International Knee Documentation Committee; MLS, Major League Soccer; MRI, magnetic resonance imaging; MMT, medial meniscus tear; RTP, return to play; SD, standard deviation; Shots OT, shots on target; SPSS, Statistical Package for the Social Sciences; TN, time-normalized.

\section{Ethics}

This study was determined to be exempt and non-human research by the Institutional Review Board at UT Health San Antonio. No individual consent was required for this research.

\section{Funding}

There is no funding to report.

\section{Disclosure}

The authors report no conflict of interest regarding the publication of this manuscript.

\section{References}

1. Chomiak J, Junge A, Peterson L, Dvorak J. Severe injuries in football players. Influencing factors. Am J Sports Med. 2000;28:58-68. doi:10.1177/28.suppl_5.s-58

2. Nawabi DH, Cro S, Hamid IP, Williams A. Return to play after lateral meniscectomy compared with medial meniscectomy in elite professional soccer players. Am J Sports Med. 2014;42(9):2193-2198. doi:10.1177/0363546514540271 Epub 2014 Jul 17. PMID: 25035175.

3. Frizziero A, Ferrari R, Giannotti E, Ferroni C, Poli P, Masiero S. The meniscus tear. State of the art of rehabilitation protocols related to surgical procedures. Muscles Ligaments Tendons J. 2013;2 (4):295-301. PMID: 23738313; PMCID: PMC3666539. 
4. Flanigan DC, Harris JD, Trinh TQ, Siston RA, Brophy RH. Prevalence of chondral defects in athletes' knees: a systematic review. Med Sci Sports Exerc. 2010;42(10):1795-1801. doi:10.1249/MSS.0b013e3181d9eea0 PMID: 20216470.

5. Logan M, Watts M, Owen J, Myers P. Meniscal repair in the elite athlete: results of 45 repairs with a minimum 5-year follow-up. $\mathrm{Am}$ J Sports Med. 2009;37(6):1131-1134. doi:10.1177/ 0363546508330138

6. Tucciarone A, Godente L, Fabbrini R, Garro L, Salate Santone F, Chillemi C. Meniscal tear repaired with Fast-Fix sutures: clinical results in stable versus ACL-deficient knees. Arch Orthop Trauma Surg. 2012;132(3):349-356. doi:10.1007/s00402-011-1391-5

7. Alvarez-Diaz P, Alentorn-Geli E, Llobet F, Granados N, Steinbacher G, Cugat R. Return to play after all-inside meniscal repair in competitive football players: a minimum 5-year follow-up. Knee Surg Sports Traumatol Arthrosc. 2016;24(6):1997-2001. doi:10.1007/s00167-014-3285-x

8. Bezuglov EN, Lyubushkina AV, Khaitin VY, et al. Prevalence of Asymptomatic Intra-articular Changes of the Knee in Adult Professional Soccer Players. Orthop J Sports Med. 2019;7 (11):2325967119885370. doi:10.1177/2325967119885370 PMID 32010730; PMCID: PMC6967194.

9. Dvorak J, Junge A. Football injuries and physical symptoms. A review of the literature. Am J Sports Med. 2000;28(5 Suppl):S39. doi:10.1177/28.suppl 5.s-3

10. Junge A, Dvorak J. Soccer injuries: a review on incidence and prevention. Sports Med. 2004;34(13):929-938. doi:10.2165/ 00007256-200434130-00004

11. Hawkins RD, Hulse MA, Wilkinson C, Hodson A, Gibson M. The association football medical research programme: an audit of injuries in professional football. $\mathrm{Br} J$ Sports Med. 2001;35(1):43-47. doi: $10.1136 /$ bjsm.35.1.43

12. Fairbank TJ. Knee joint changes after meniscectomy. $J$ Bone Joint Surg Br. 1948;30B(4):664-670. doi:10.1302/0301-620X.30B4.664

13. Brelin AM, Rue J-PH. Return to Play Following Meniscus Surgery. Clin Sports Med. 2016;35(4):669-678. doi:10.1016/j. csm.2016.05.010
14. Stein JM, Yayac M, Conte EJ, Hornstein J. Treatment Outcomes of Meniscal Root Tears: a Systematic Review. Arthrosc Sports Med Rehabil. 2020;2(3):e251-e261. doi:10.1016/j.asmr.2020.02.005

15. Eberbach H, Zwingmann J, Hohloch L, et al. Sport-specific outcomes after isolated meniscal repair: a systematic review. Knee Surg Sports Traumatol Arthrosc. 2018;26(3):762-771. doi:10.1007/s00167-0174463-4

16. Tegner Y, Lysholm J. Rating systems in the evaluation of knee ligament injuries. Clin Orthop Relat Res. 1985;198:43-49.

17. Briggs KK, Lysholm J, Tegner Y, Rodkey WG, Kocher MS, Steadman JR. The reliability, validity, and responsiveness of the Lysholm score and Tegner activity scale for anterior cruciate ligament injuries of the knee: 25 years later. Am J Sports Med. 2009;37 (5):890-897. doi:10.1177/0363546508330143

18. Briggs KK, Kocher MS, Rodkey WG, Steadman JR. Reliability, validity, and responsiveness of the Lysholm knee score and Tegner activity scale for patients with meniscal injury of the knee. $J$ Bone Joint Surg Am. 2006;88(4):698-705.

19. Kong DH, Yang SJ, Ha JK, Jang SH, Seo JG, Kim JG. Validation of functional performance tests after anterior cruciate ligament reconstruction. Knee Surg Relat Res. 2012;24(1):40-45. doi:10.5792/ksrr.2012.24.1.40

20. Pujol N, Bohu Y, Boisrenoult P, Macdes A, Beaufils P. Clinical outcomes of open meniscal repair of horizontal meniscal tears in young patients. Knee Surg Sports Traumatol Arthrosc. 2013;21 (7):1530-1533. doi:10.1007/s00167-012-2099-y

21. Vanderhave KL, Moravek JE, Sekiya JK, Wojtys EM. Meniscus tears in the young athlete: results of arthroscopic repair. J Pediatr Orthop. 2011;31(5):496-500. doi:10.1097/BPO.0b013e31821ffb8d

22. Griffin JW, Hadeed MM, Werner BC, Diduch DR, Carson EW, Miller MD. Platelet-rich plasma in meniscal repair: does augmentation improve surgical outcomes? Clin Orthop Relat Res. 2015;473 (5):1665-1672. doi:10.1007/s11999-015-4170-8

23. Nakayama H, Kanto R, Kambara S, et al. Clinical outcome of meniscus repair for isolated meniscus tear in athletes. Asia Pac J Sports Med Arthrosc Rehabil Technol. 2017;10:4-7.

\section{Publish your work in this journal}

Open Access Journal of Sports Medicine is an international, peerreviewed, open access journal publishing original research, reports, reviews and commentaries on all areas of sports medicine. The manuscript management system is completely online and includes a very quick and fair peer-review system. Visit http://www.dovepress. com/testimonials.php to read real quotes from published authors. 